\title{
EQUILIBRIUM ISOTHERM, KINETIC MODELING, AND CHARACTERIZATION STUDIES OF CADMIUM ADSORPTION IN AN AQUEOUS SOLUTION BY ACTIVATED CARBON PREPARED FROM BAUHINIA PURPUREA LEAVES
}

\author{
H. Joga Rao ${ }^{1, *}$, P. King ${ }^{2}$ and Y. Prasanna Kumar ${ }^{3}$ \\ ${ }^{1}$ Department of Chemical Engineering, GMR Institute of Technology, \\ Rajam-532127, Andhra Pradesh, India. \\ ${ }^{2}$ Department of Chemical Engineering, Andhra University College of, Engineering, \\ Visakhapatnam-530008, Andhra Pradesh, India. \\ ${ }^{3}$ Principal, Visakha Institute of Engineering and Technology, \\ Visakhapatnam-530027, Andhra Pradesh, India. \\ *E-mail: jogarao.h@gmrit.org
}

\begin{abstract}
Cadmium is the toxic metal selected for adsorption in this study and adsorbent of interest was activated carbons prepared from Bauhinia Purpurea leaves as a plant biomass. Batch experimental studies conducted for the given adsorbent imparted that the experimental data were fitted very well with the Freundlich isotherm for the Cadmium adsorption process. The sorption kinetic studies for a given adsorbent indicated that the adsorption tends to follow the pseudo-second order. The suitability of kinetic models followed in the order by Second - order kinetic model > First - order model >Elovich model > Intra-particle diffusion model.The mean adsorption energy E value of Cadmium adsorption was decreased with increasing isothermal temperature (303-323K) from 1.936 to 1.79 $\mathrm{kJ} / \mathrm{mole}$. It was observed that the scope of an ordinary free energy credited to physical adsorption and the force of attraction between the adsorbate and adsorbent is very weak, therefore this type of adsorption can be easily reversed by heating or by decreasing the pressure. The characterization of metal-adsorbent interactions before and after adsorption was studied using SEM, FTIR and XRD techniques. FTIR spectrum of raw activated carbon of Bauhinia Purpurea leaves reveals that there were a large number of hydroxyl and carboxyl groups present on the surface of the adsorbent, which possibly reacted with metal ions in aqueous solution.

Keywords:Bauhinia Purpurea leaves, Equilibrium Isotherm, Kinetic Modeling,Characterization.
\end{abstract}

(C) RASĀYAN. All rights reserved

\section{INTRODUCTION}

The liquid pollutants discharged from industrial sources to the ecosystem, the usable water has decreased drastically and the cost of purifying the water has increased dramatically. The rapid pace of population growth, industrialization and improper planning of urban development activities have been severely contributing to the contamination of water and soil systems. Industries produce much wastewater and sludge containing heavy metal (Zinc, Copper, Nickel, Lead, Chromium, Cadmium, Mercury, etc.) ions with various concentrations, which are very toxic and carcinogenic to the human and other living organisms ${ }^{1,2}$.Cadmium, an element which is spread widely and found naturally, but a rare element. The leachates from hazardous waste sites and industrial wastewaters seldom contaminate the groundwater with high levels of cadmium. $0.005 \mathrm{mg} / \mathrm{L}$ is set as the maximum cadmium concentration in the domestic water supplies by the World Health Organization and the EUD erective ${ }^{3}$.Indian standard code IS: 10500 has set the maximum permissible limit of $\mathrm{Cd}$ in effluents while discharging them into the municipal sewers and surface waters as 2 and $1 \mathrm{mg} / \mathrm{L}$ respectively. Moreover, IS: 10500 has set the maximum permissible limit of $\mathrm{Cd}$ in drinking water as $0.003 \mathrm{mg} / \mathrm{L}^{4}$. From this study, it is evident that adsorption has

Rasayan J. Chem., 11(3), 1376-1392(2018)

http://dx.doi.org/10.31788/RJC.2018.1134035

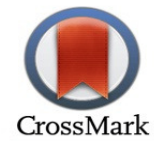


been used by most of the researchers during the last few decades and it has proved to be a very efficient and economic process. Several methods which were used for the treatment of wastewater include precipitation, ion exchange, coagulation, and reverse osmosis ${ }^{5,6}$.However, these methods are either less effective or more expensive in treating high volumes; require the use of expensive chemicals and low metal concentration in aqueous form. Most of these processes suffer from high operating cost and recurring expenses such as chemicals, which are not suitable for the small-scale industries.

Adsorption is one of the most versatile and widely used techniques for the removal of metal ions. There are numerous materials used as adsorbents like fullers-earth, zeolite, activated alumina, biomass, resins, activated carbons, etc. Activated carbon is the most effective and widely used adsorbent because it has the large specific surface area, micro-porous structure, and excellent adsorption ability. Activated carbon has been the water industry's standard adsorbent for the reclamation of municipal and industrial wastewater for potable use for more than three decades. Despite its prolific use of the water and wastewater treatment plants, activated carbon remains an expensive material. In recent years, research interest in the production of low $\operatorname{cost}^{7-9}$ activated carbon produced from unused materials has grown. Low cost activated carbons are prepared by thermo-chemical methods of various unused materials and plant biomass used to remove heavy metals from effluents ${ }^{10,11}$. With this brief introduction about the heavy metal pollution and importance of the cadmium removal in particular from wastewater streams, an attempt has been made to study the use of low cost activated carbon from Bauhinia Purpurea leaves as an adsorbent to treat the simulated metal solutions ${ }^{12}$.Linear isotherm models, Langmuir, Freundlich, Temkin and DubininRadushkevich (D-R) were tested in the equilibrium studies of Cadmium metal ion using the adsorbent. The fitness of equilibrium data from the pseudo first order, pseudo-second order, Elovich, and Intraparticle diffusion models were investigated and compared for the two adsorbents. Scanning Electron Microscopy (SEM), Fourier Transform Infrared Spectroscopy (FTIR) and X-ray diffraction (XRD) is used for the characterization of the adsorbents.

\section{Material and Chemicals}

\section{EXPERIMENTAL}

The following material and chemicals are used for the preparation and activation of adsorbent: Bauhinia Purpurea leaves, Cadmium Nitrate $\mathrm{Cd}\left(\mathrm{No}_{3}\right)_{2}$, Hydrochloric Acid $(\mathrm{HCl})$, and Zinc Chloride $\left(\mathrm{ZnCl}_{2}\right)$.

\section{Preparation of Adsorbent}

The adsorbents, waste tires and Bauhinia Purpurea leaves used in the present study were collected in Rajam and Srikakulam, Andhra Pradesh, INDIA.The Bhuhinia Purpurea leaves were washed several times with deionized water until the wash water contains no dirt. These washed leaves were completely dried under sunlight for 30 days and were cut into small pieces and powdered using a domestic mixer. The powder,dried in an oven at $100^{\circ} \mathrm{C}$ for $120 \mathrm{~min}$. The dried material was now placed in the cooker for carbonization and it was heated continuously for $10 \mathrm{~min}$. The dried material was activated to $650^{\circ} \mathrm{C}$ for $120 \mathrm{~min}$ in a covered silica crucible by heating in a muffle - furnace ${ }^{13,14}$. After that, taken $100 \mathrm{~g}$ of carbon powder from a muffle furnace and mixed with $100 \mathrm{~g} \mathrm{ZnCl}_{2}$ dissolved in $500 \mathrm{ml}$ of distilled water containing $22 \mathrm{~g}$ of $\mathrm{HCl}$. The chemically treated material was left overnight and carbonized. The carbonized material was refluxed with $10 \% \mathrm{HCl}$ solution for $180 \mathrm{~min}$ and filtered. This was followed by drying of the material at $100^{\circ} \mathrm{C}$ for $24 \mathrm{hrs}$. The dried product was sieved to the desired particle size range of $74-177 \mu \mathrm{m}$.

\section{Batch Adsorption Experimental Studies}

The adsorption studies were conducted in the exploratory conditions of various effective process parameters of $\mathrm{pH}$ 2-10 for cadmium, contact time of 2-120 min, metal ion concentration ranges from 2-10 $\mathrm{mg} / \mathrm{L}$, the dosage of the adsorbent 0.025-0.15 g, and the particle size of the adsorbent varies from 74 (200 mesh) -177 (80 mesh) $\mu \mathrm{m}$. The agitation speed of $250 \mathrm{rpm}$ was kept constant in the orbital shaker with the suitable time interims from $2-120 \mathrm{~min}$. The mixed adsorbent solutions were taken out and filtered by Watmann filter paper and analyzed for metal ion concentration in an Atomic Absorption Spectrophotometer (Perkin Elmer model-3100). Batch experiments were conducted at various 
temperatures of the metal solution utilizing orbital shaker from $303 \mathrm{~K}-323 \mathrm{~K}$ with an optimum contact time of $50 \mathrm{~min}$ at $\mathrm{pH}$ values of 6.5 .

\section{Metal Adsorption Capacity}

After experimentation, the amount of metal deposited on the adsorbent surface was calculated by using the following equation:

$$
q_{t}=\frac{V\left(C_{i}-C_{f}\right)}{1000 w}
$$

Where $q_{t}$ is the amount of metal deposited on the adsorbent surface $(m g / g), C_{i}$ is the initial solute concentration in the solution before adsorption $(\mathrm{mg} / \mathrm{L}), C_{f}$ is the final concentration of solute in the solution after adsorption $(m g / L), V$ is the volume of metal solution $(L)$ and $w$ is the dosage of the adsorbent $(g)$.

\section{Freundlich and Langmuir Isotherms}

The adsorption isotherms indicate the distribution of adsorbed molecules between the liquid phase and solid phase when the adsorption process reaches an equilibrium state. The application of the isotherm equation is compared by judging the correlation coefficients $R^{2}$. Isotherms are calculated under existing equilibrium conditions.Freundlich isotherm model describes the ratio of the amount of metal adsorbed onto a given mass of adsorbent to the concentration of the metal in the solution. This model can be applied to multi-layer adsorption, with non-uniform distribution of adsorption heat and affinities over the heterogeneous surface and can be represented by the equation in linear form as: ${ }^{15,16}$

$$
\ln q_{e q}=\ln K_{f}+\frac{1}{n_{f}} \ln c_{e q}
$$

Where $q_{e q}$ is the amount of metal deposited on the adsorbent surface per unit mass of adsorbent (mg/g), $C_{e q}$ is the equilibrium concentration $(\mathrm{mg} / \mathrm{L})$, and $k_{f}\left((m g / g) /(L / g)^{n}\right)$ is the Freundlich adsorption constant related to adsorption capacity and $1 / n_{f}$, a dimensionless constant, which can be used to explain the extent of adsorption and the adsorption intensity between the solute concentration and adsorbent respectively. A plot of $\ln q_{e}$ versus $\ln C_{e q}$ based on experimental data gives a straight line, from the slope of which $1 / n_{f}$ may be calculated and $k_{f}$ may be evaluated from the intercept. Freundlich isotherm is widely applied in heterogeneous systems, particularly for organic compounds or highly interactive species on activated carbon and molecular sieves.

The Langmuir mathematical statement was used for the estimation of maximum adsorption capacity corresponding to the complete monolayer scope on the adsorbent surface, and after that no further adsorption happens. Thereby, the Langmuir represents the equilibrium distribution of metal ions between the solid and liquid phases ${ }^{17,18}$. The Langmuir isothermal model is presented by the following equation

$$
\frac{1}{q_{e q}}=\frac{1}{q_{\max } K_{L} C_{e q}}+\frac{1}{q_{\max }}
$$

Where $q_{\max }$ is the adsorption binding capacity, that is, the maximum adsorption upon complete saturation of the adsorbent surface, and $K_{L}(L / g)$ is an affinity of adsorbent towards adsorbate. A linear plot of $1 / q_{e q}$ versus $C_{e q}$ was drawn to determine $q_{\max }$ and $K_{L}$. From the shape of the isotherm, one can predict whether an adsorption process is favorable or unfavorable. The essential feature of the Langmuir isotherm can be expressed by means of $R_{\mathrm{L}}$, a dimensionless constant referred to a separation factor or equilibrium parameter. $R_{L}$ is calculated using the following equation:

$$
R_{L}=\frac{1}{1+K_{L} C_{i}}
$$


The value of the separation factor $R_{L}$ describes the nature of adsorption of the isotherm.

\section{Temkin and Dubinin-Radushkevich Isotherms}

The Temkin isotherm model assumes that the heat of adsorption of all the molecules in layer decreases linearly with coverage due to adsorbent-adsorbate interactions, and that the adsorption is characterized by a uniform distribution of the bonding energies, up to some maximum binding energy. The linear form of Temkin equation is: ${ }^{19}$

$$
q_{e q}=\frac{R T}{b_{T}} \ln A_{T}+\frac{R T}{b_{T}} \ln C_{e q}
$$

Where $A_{T}(\mathrm{~L} / \mathrm{mg})$ and $b_{T}(\mathrm{~J} / \mathrm{mole})$ are Temkin isotherm constants. A plot of $q_{e q}$ versus $\ln C_{e q}$ enables the determination of the isotherm constants $A_{T}$ and $b_{T}$.

Dubinin-Radushkevich isotherm is an empirical model, applied to examine the adsorption mechanism with a Gaussian energy distribution onto a heterogeneous surface. The model has frequently effectively fitted high solute affinity and the intermediate range of concentrations. The methodology was usually applied to differentiate between the physical and chemical adsorption of metal ions, with its mean free energy (E). The linear form of the D-R isotherm model is given by:20,21

$\ln q_{e q}=\ln q_{o}-K_{d} \varepsilon^{2}$

The parameter $\varepsilon$ is Polanyi potential computed by an empirical equation:

$$
\varepsilon=R T \ln \left(1+\frac{1}{C_{e}}\right)
$$

Where, $K_{d}\left(\mathrm{Mol}^{2} / \mathrm{J}^{2}\right)$ is related to the free energy of adsorption per mole of the adsorbate, and $q_{o}(\mathrm{mg} / \mathrm{g})$ is the Dubinin-Radushkevich isotherm constant related to the degree of adsorbate adsorption by the adsorbent surface. The values of $q_{o}$ and $K_{d}$ can be obtained by plotting $\ln q_{e}$ versus $\varepsilon^{2}$. The mean free energy of adsorption process was evaluated by the following equation:

$$
E=\frac{1}{\sqrt{2 K_{d}}}
$$

The magnitude of $\mathrm{E}$ can be utilized for assessing the kind of adsorption. The adsorption behavior can be depicted as the physical adsorption when the mean adsorption energy (E) is somewhere around 1 to 8 $\mathrm{kJ} / \mathrm{mol}$. However, the value of mean adsorption energy (E) is more than $8 \mathrm{KJ} /$ mail indicates that the adsorption process is chemisorption ${ }^{22,23}$.

\section{Pseudo-First and Second Order Kinetic Models}

A number of models with varying degrees of complexity have been developed to describe the kinetics of metal adsorption in batch systems ${ }^{24}$. Due to the presence of a greater number of metal ions in industrial wastewater, the adsorption equilibrium was reached much faster due to faster occupancy of adsorption sites by metal ions. The pseudo-first order kinetic model presented by Lagergren ${ }^{25}$ is mostly suited for solutes of lower concentrations. The pseudo-first order kinetic model can be expressed as:

$$
\ln \left(q_{e q}-q_{t}\right)=\ln q_{e q}-k_{f} t
$$

Where, $q_{t}(\mathrm{mg} / \mathrm{g})$ is the adsorption intensity at time $\mathrm{t} ; q_{e q}(\mathrm{mg} / \mathrm{g})$ is the adsorption intensity at equilibrium; $k_{f}(1 / \mathrm{min})$ is the rate constant of the first-order adsorption. Thus, a plot of $\ln \left(q_{e q}-q_{t}\right)$ vs $t$ will be a straight line with $k_{f}$ as slope and $\ln q_{e q}$ as an intercept.

The pseudo-second order model proposed by Ho and McKay ${ }^{8}$ can be used to explain the sorption kinetics, if the rate of sorption is found to be a second-order mechanism. The pseudo-second order model can be written as:

$$
\frac{t}{q_{t}}=\frac{1}{k_{s} q_{e q}^{2}}+\frac{1}{q_{e q}}(t)
$$


The parameters, slope and intercept can be estimated by plotting $t / q_{t}$ against $t$ of the equation (10).

Intra - Particle Diffusion and Elovich Kinetic Models

Weber and Morris ${ }^{8,16}$ presented the intra-particle diffusion kinetic model as:

$$
q_{t}=k_{p} t^{0.5}+C
$$

Where $k_{P}$ represents intra-particle diffusion rate constant and $\mathrm{C}$ is a parameter, that symbolizes the external convective mass transfer from the bulk liquid to the surface of the solid as it delivers the same unit as $q_{t}$. It gives an estimate of the thickness of the boundary layer, i.e., the greater the $\mathrm{C}$ value, the higher the boundary layer effect. The values are obtained by fitting $q_{t}$ vs $\sqrt{t}$. If the plot passes through the origin, $\mathrm{C}=0$, the intra-particle diffusion is the rate-limiting step, according to Weber and Morris ${ }^{26}$. But, if the plot generates multi linear proportions, there may be considerable rate-limiting steps in the adsorption ${ }^{27}$.The Elovich equation is given as follows,

$$
q_{t}=\frac{1}{\gamma} \ln (\alpha \gamma)+\frac{1}{\gamma} \ln t
$$

Where $\gamma$ is desorption constant $(\mathrm{g} / \mathrm{mg})$ and $\alpha$ is the initial adsorption rate $(\mathrm{mg} / \mathrm{g} \mathrm{min}) . q_{t}$ is the amount of metal removed at time $t$. The constants are obtained from the slope and intercept of a straight line plot of $q_{t}$ versus $\ln t$. The initial adsorption rate is determined using this Elovich equation.

\section{Characterization of the Adsorbents}

Scanning Electron Microscopy (SEM) uses a focused beam of high-energy electrons to generate a variety of signals at the surface of solid specimens. In most SEM microscopy applications, data are collected over a selected area of the surface of the sample and a two-dimensional image is generated that displays spatial variation in properties including chemical characterization, texture and orientation of materials ${ }^{28}$. The SEM is also capable of performing analyses of selected point locations on the sample. This approach is especially useful in qualitatively or semi-quantitatively determining chemical compositions, crystalline structure and crystal orientations.

$\mathrm{X}$-ray diffraction (XRD) is an analytical technique primarily used for a quick identification of phases in a crystalline material and the unit cell dimensions. The sample is scanned through a range of $2 \theta$ angles, so that all possible diffraction directions of the lattice may be attained. The diffraction peaks are converted to d-spacings to simplify the identification of the mineral since each mineral has distinctive d-spacings. This can be achieved by comparing the d-spacings with standard reference patterns. To understand the adsorption process, it is very important to know the chemical structure of the adsorbents. FTIR plays an important role in identifying the characteristic functional groups responsible for the adsorption of heavy metals. FTIR spectra of the adsorbents were obtained using an FTIR spectrometer ${ }^{29,} 30$. The plot, IR transmission vs frequency helps to identify the material when compared to reference spectra.

\section{RESULTS AND DISCUSSION}

The experimental data were obtained for the adsorption of cadmium from aqueous solutions using activated carbons prepared fromBauhinia Purpurea leaves as an adsorbent.

\section{Freundlich and Langmuir Adsorption Isotherms}

The experimental data were tested for the fitness of the Freundlich isotherm model by using the liner graphical method. The adsorption data were analyzed by plotting $\ln q_{e}$ verses $\ln C_{e}$ and shown in Fig.- 1 . The values of Freundlich constants and correlation coefficients $\left(R^{2}\right)$ obtained from the linear Freundlich plots for Cadmium was given in Table 1. The value of the coefficient of determination was close to unity $\left(R^{2}=0.982\right)$. The values of $\frac{1}{n_{f}}<1(0.261)$, indicate that the intensity of adsorption of Cadmium onto activated carbon of Bauhinia Purpurea leaves as an absorbent surface was high. The high value of adsorption capacity constant $K_{f}$ (0.65) obtained indicated the fast uptake capacity of the adsorbent. 
Similar trends were obtained for other isothermal temperatures for the Cadmium. The $K_{f}$ value of Cadmium adsorption was increased from 0.65 to $1.104(\mathrm{mg} / \mathrm{g}) /(\mathrm{L} / \mathrm{g})^{\mathrm{n}}$ with an increase in temperature $(303 \mathrm{~K}-323 \mathrm{~K})$, reflect that deposition rate is more at higher effluent isothermal temperatures. The magnitudes of $K_{f}$ and $\frac{1}{n_{f}}$ show easy separation of metal ions from effluents with a high adsorptive capacity of the activated carbons prepared from Bauhinia Purpurea leaves, especially at $303 \pm 1 \mathrm{~K}$ and $\mathrm{pH}$ $=6.5\left(t: 50 \mathrm{~min}\right.$ and $\left.C_{\mathrm{i}}: 2 \mathrm{mg} / \mathrm{L}\right)$. Fig. 2 shows that $1 / q_{e}$ was plotted against $1 / C_{e q}$ yielding a straight line with $R^{2}=0.951$, indicating that adsothe rption data fitted well with the Langmuir model. The value of $q_{\max }$ is $0.923 \mathrm{mg} / \mathrm{g}$ at $2 \mathrm{mg} / \mathrm{L}$ was calculated from the slope of the linear plot, whereas the value of $K_{L}$ was derived from the intercept and compiled in Table-1.The separation factor $\left(R_{L}\right)$ was estimated for the Cadmium at different initial metal concentrations by using equation (4) shown in Fig.-3. The values of $R_{L}$ for cadmium were found to be in the range of 0.02 to 0.1 , respectively. These results revealed that the adsorption of cadmium onto activated carbon from Bauhinia Purpurea leaves adsorbent was favorable and has an $R_{L}$ value between 0 and 1 .

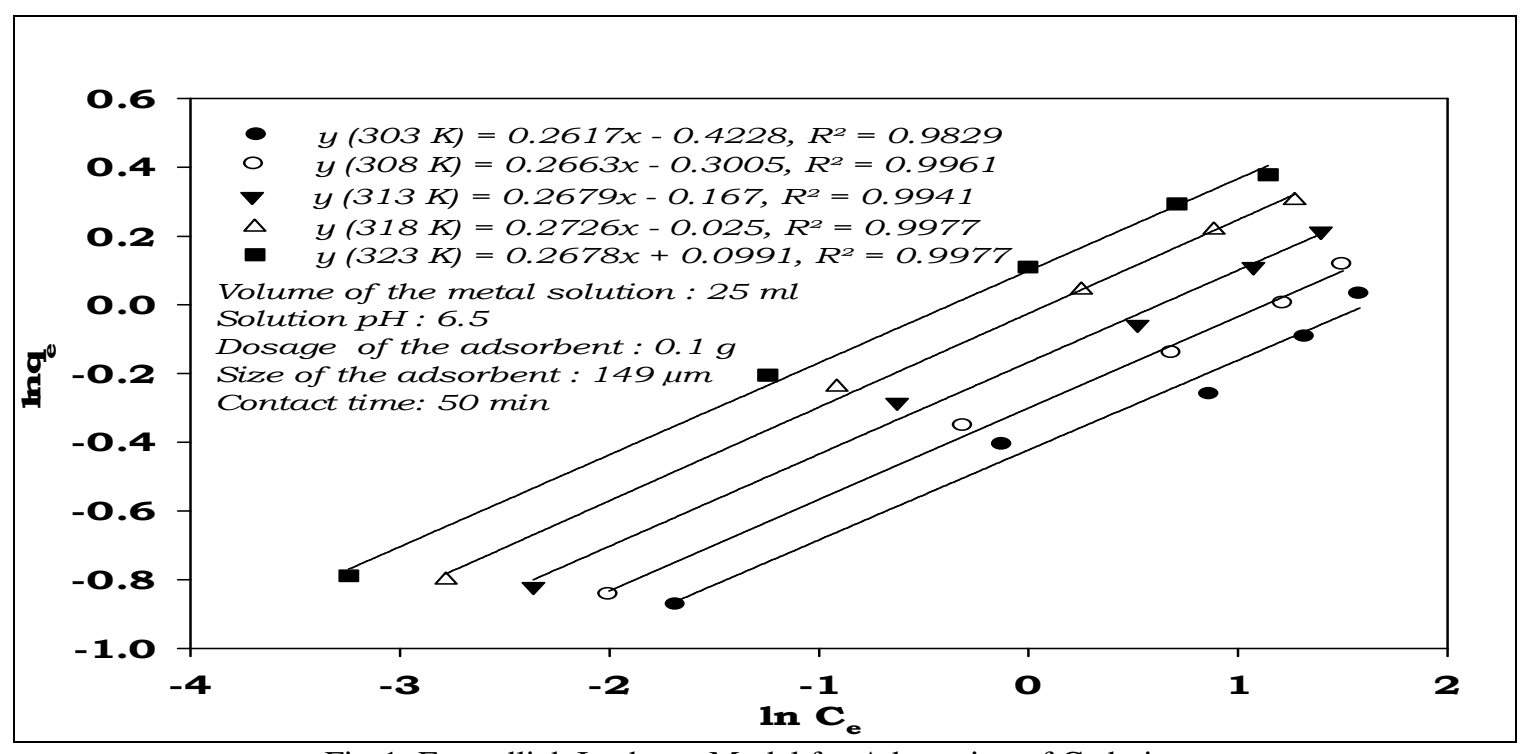

Fig-1: Freundlich Isotherm Model for Adsorption of Cadmium.

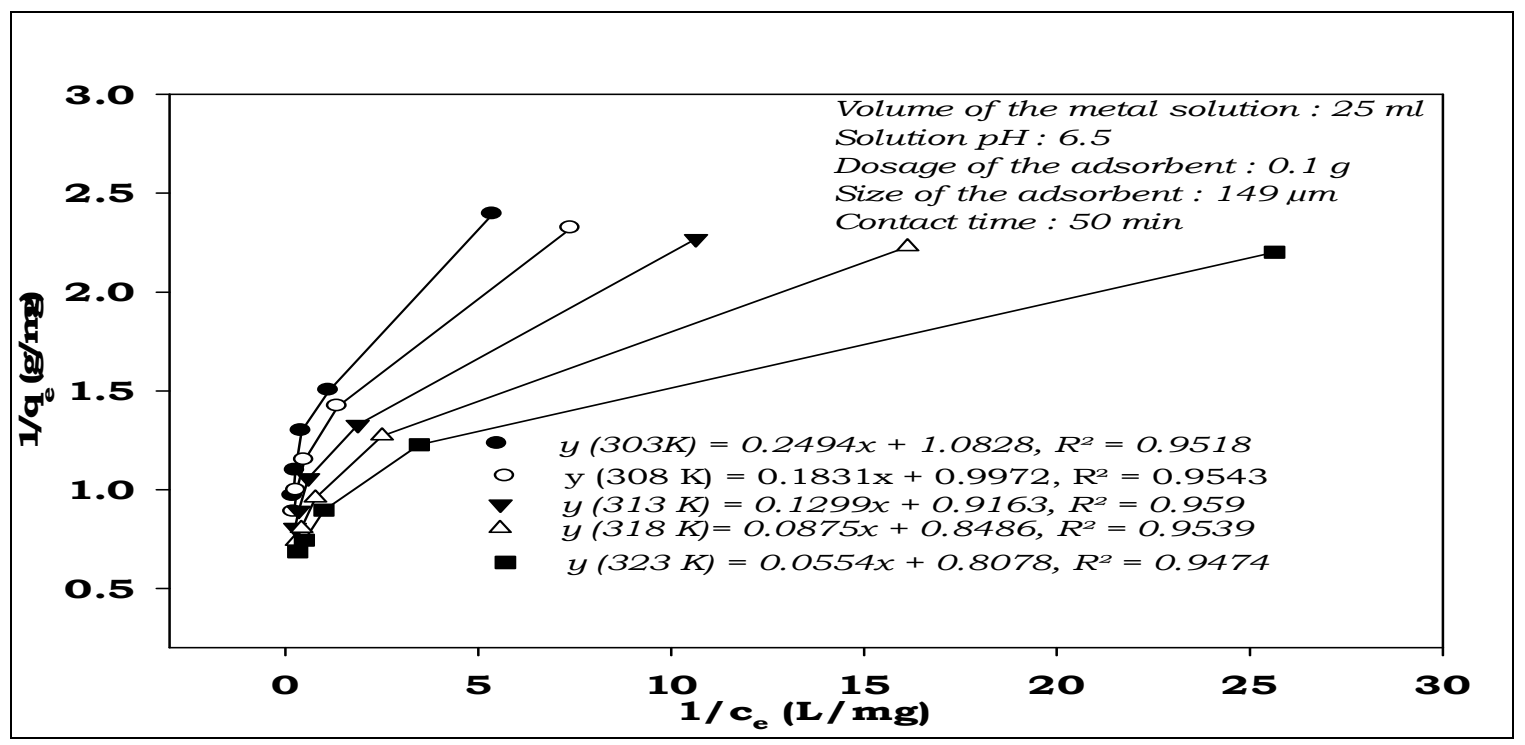

Fig-2: Langmuir Isotherm Model for Adsorption of Cadmium 


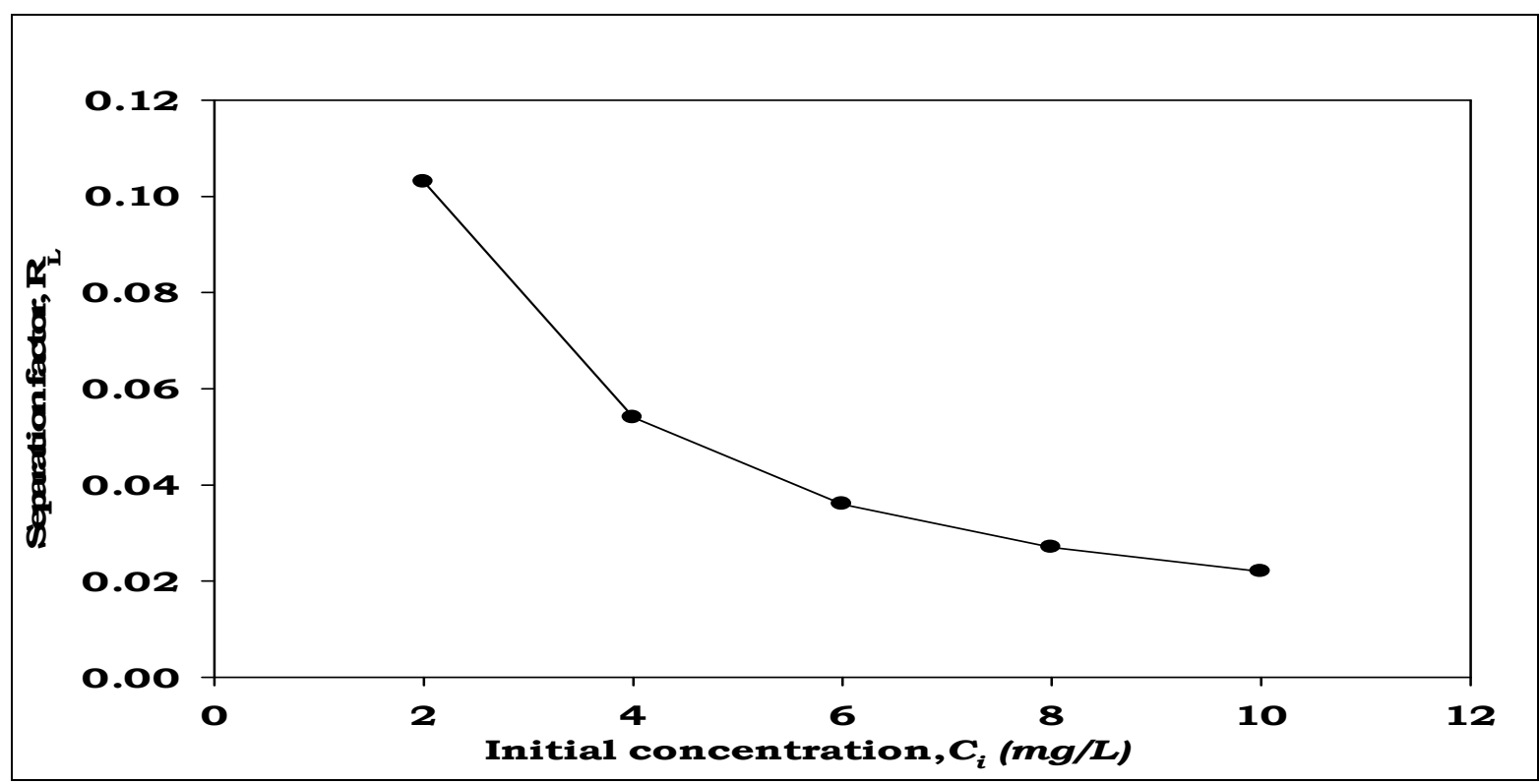

Fig-3: Separation Factor for Adsorption of Cadmium.

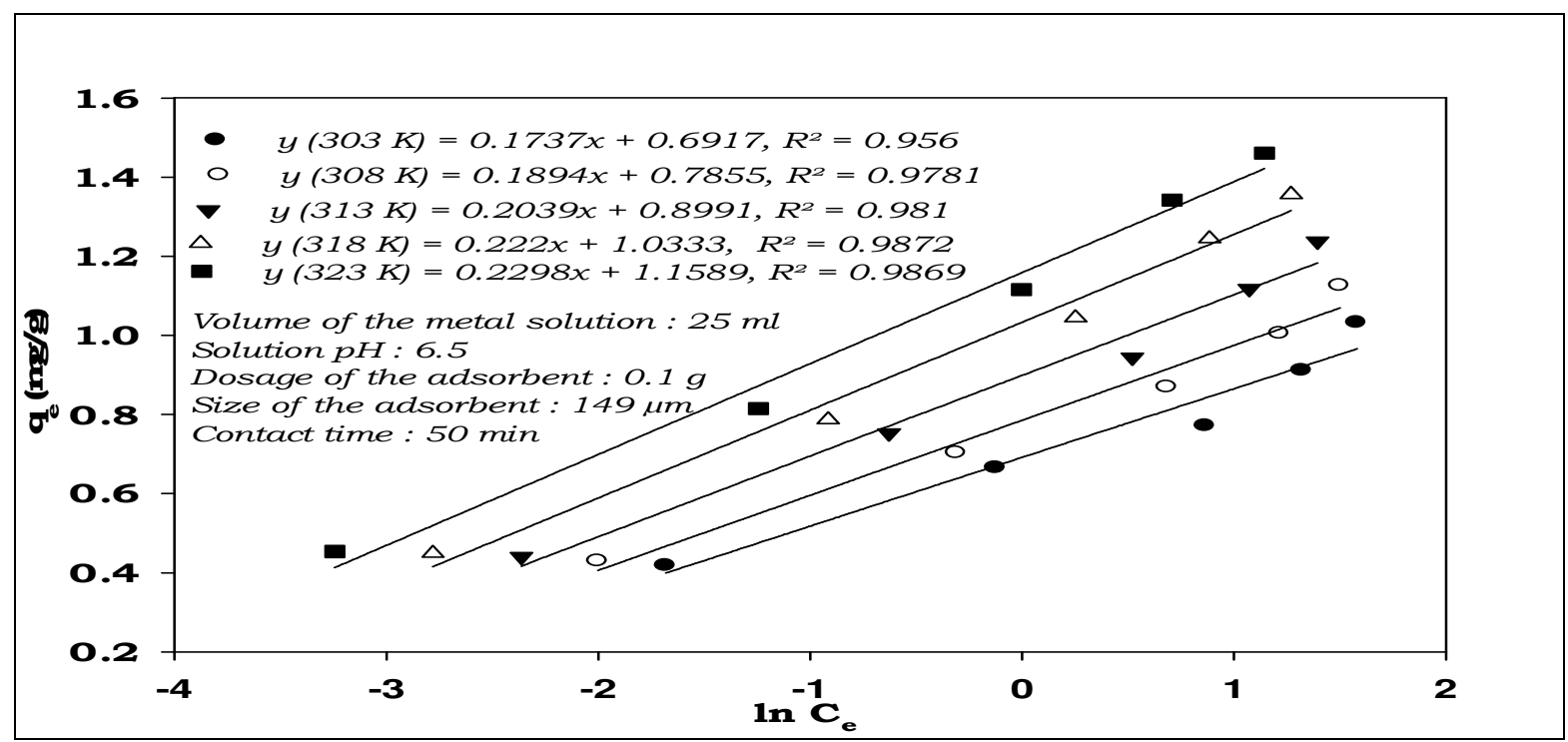

Fig-4: Temkin Isotherm Model for Adsorption of Cadmium.

\section{Temkin and Dubinin-Radushkevich Adsorption Isotherms}

The adsorption data were analyzed according to the linear form of Temkin model and is shown in Fig.-4. The linear Temkin isotherm constants $A_{T}$ and $b_{T}$, were determined from the slope and intercept of the plots of $q_{e}$ versus $\ln C_{e}$, respectively, and are tabulated along with corresponding correlation coefficients in Table-1.The $R^{2}$ value for Cadmium was found to 0.956. These high correlation coefficients suggested that a uniform binding energy was increased due to the interaction of the metal ions. These values also indicated that the adsorption process may be due to the heterogeneous surface coverage and the possible involvement of chemisorption. The linear plot of $\mathrm{D}-\mathrm{R}$ isotherm is shown in Fig.-5. The values of D-R isotherm parameters were calculated by using equations (6,7 and 8) and shown in Table-1. The mean adsorption energy $\mathrm{E}$ value of Cadmium adsorption was decreased with increasing isothermal temperature (303-323K) from 1.936 to $1.79 \mathrm{~kJ} / \mathrm{mole}$. It was observed that the scope of an ordinary free energy credited to physical adsorption and the force of attraction between the adsorbate and adsorbent is very weak, therefore this type of adsorption can be easily reversed by heating or by decreasing the pressure.From the Table-1.For the given initial metal concentration of the solution, it was observed that 
the adsorption data were very well represented by Freundlich isotherm with an average higher correlation coefficient of 0.983; followed by Langmuir, Temkin and D-R with a correlation coefficient of 0.951 , 0.956 and 0.825 , respectively.

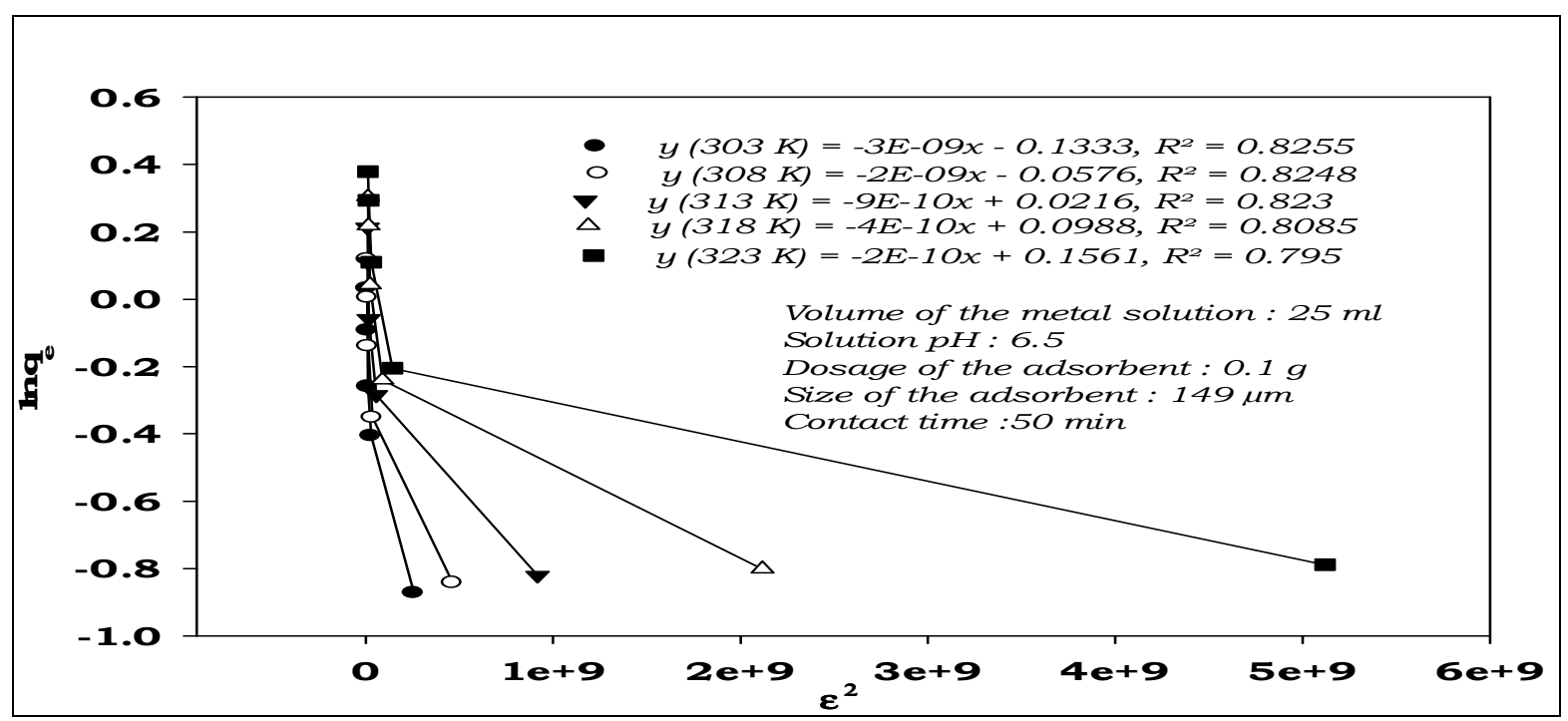

Fig.-5: Dubinin - Radushkevich Isotherms for Adsorption of Cadmium.

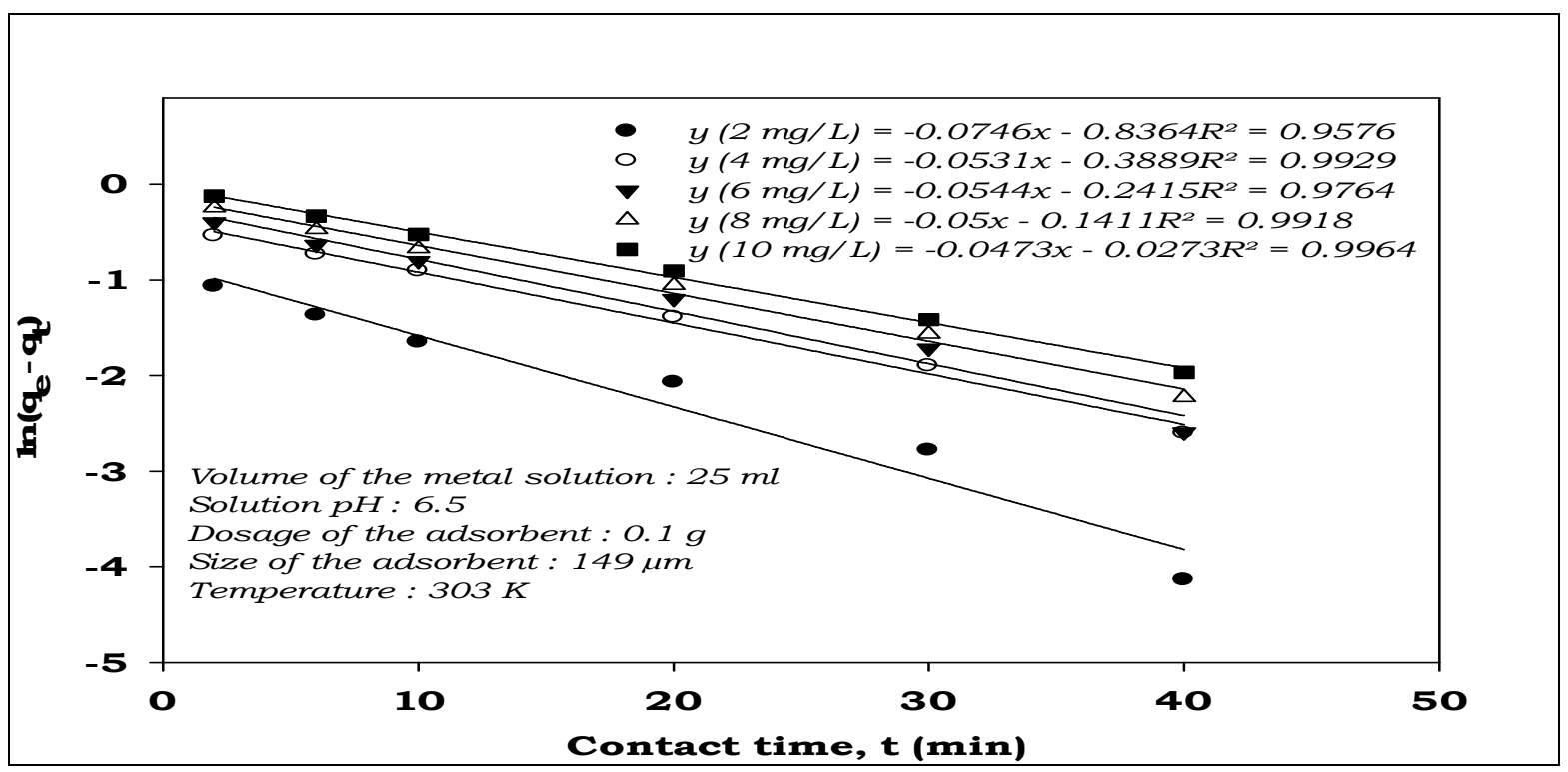

Fig.-6: First- Order Kinetic Model for Adsorption of Cadmium.

\section{Pseudo-First and Second Order Kinetic Models}

The experimental results were analyzed to test the kinetic model and the linear plots of $\ln \left(q_{e}-q_{t}\right)$ versus $t$ for Cadmium adsorption was shown in Fig.-6. The calculated first-order rate constants $\left(k_{f}\right)$ and their corresponding linear regression, correlation coefficient values are compiled in Table- 2 . The linear regression correlation coefficient value $R^{2}$ found in the range of 0.959 to 0.996 , which shows that the correlation coefficients were very high, the experimental $q_{e}$ values did not match with the calculated $q_{e}$ values. This implies that the adsorption of Cadmium onto activated carbon prepared from Bauhinia Purpurea leaves adsorbent did not follow the first-order kinetics. Figure-7 shows the plot of second order kinetic model for the Cadmium, The pseudo-second order rate constant $k_{s}$, the calculated $q_{e q}$ value and 


\section{RASĀYAN J. Chem.}

Vol. 11 | No. 3 |1376 - 1392| July - September | 2018

the corresponding linear regression correlation coefficient values $R^{2}$ are given in Table-3. The results indicate that the experimental $q_{e}$, and calculated $q_{e}$ values are very close to each other and also $R^{2}$ value is closer to unity. The high $R^{2}$ value indicates that the experimental data were well correlated to the secondorder kinetic equation.

Table -1: Isotherm Constants for Cadmium Adsorption at Ci: 2-10 mg/L,w: 0.1g,d: $149 \mu \mathrm{m}, \mathrm{T}: 303-323 \mathrm{~K}, \mathrm{pH}: 6.5$ and t: 50 min.

\begin{tabular}{c|c|c|c|c|c|c}
\hline Isotherm model & Parameter & \multicolumn{5}{|c}{ Solution temperature $(\mathrm{K})$} \\
\hline \multirow{4}{*}{ Freundlich } & & 303 & 308 & 313 & 318 & 323 \\
\cline { 2 - 7 } & $\mathrm{K}_{\mathrm{f}}(\mathrm{mg} / \mathrm{g}) /(\mathrm{L} / \mathrm{g})^{\mathrm{n}}$ & 0.65 & 0.74 & 0.846 & 0.975 & 1.104 \\
\cline { 2 - 7 } & $\mathrm{n}_{\mathrm{f}}$ & 3.82 & 3.75 & 3.732 & 3.66 & 3.73 \\
\cline { 2 - 7 } & $\mathrm{R}^{2}$ & 0.982 & 0.996 & 0.994 & 0.997 & 0.997 \\
\hline \multirow{4}{*}{ Langmuir } & $\mathrm{q}_{\max }(\mathrm{mg} / \mathrm{g})$ & 0.923 & 1.00 & 1.090 & 1.178 & 1.237 \\
\cline { 2 - 7 } & $\mathrm{K}_{\mathrm{L}}(\mathrm{L} / \mathrm{g})$ & 4.344 & 5.45 & 7.060 & 9.700 & 14.59 \\
\cline { 2 - 7 } & $\mathrm{R}^{2}$ & 0.951 & 0.954 & 0.959 & 0.953 & 0.942 \\
\cline { 2 - 7 } & $\mathrm{R}_{\mathrm{L}}=1 /\left(1+\mathrm{K}_{\mathrm{L}} \mathrm{C}_{\mathrm{i}}\right)$ & 0.103 & 0.084 & 0.066 & 0.049 & 0.033 \\
\hline \multirow{4}{*}{$\begin{array}{c}\text { Temkin } \\
\text { Dubinin - }\end{array}$} & $\mathrm{A}_{\mathrm{T}}(\mathrm{L} / \mathrm{g})$ & 53.63 & 63.26 & 82.22 & 105.0 & 154.9 \\
\cline { 2 - 7 } & $\mathrm{b}_{\mathrm{T}}(\mathrm{L} / \mathrm{mg})$ & 14502 & 13520 & 12762 & 11909 & 11685 \\
\cline { 2 - 7 } & $\mathrm{R}^{2}$ & 0.956 & 0.978 & 0.981 & 0.987 & 0.986 \\
\hline & $\mathrm{K}_{\mathrm{d}}$ & $7.5 * 10^{-10}$ & $1.6 * 10^{-5}$ & $1.8 * 10^{-35}$ & $9 * 10^{-14}$ & \multirow{2}{*}{$4 * 10^{-5}$} \\
\cline { 2 - 7 } & $\left(\mathrm{Mol}^{2} k J{ }^{-2}\right)$ & 0.133 & 0.056 & 0.0216 & 0.098 & $10^{-5}$ \\
\cline { 2 - 7 } & $\mathrm{q}_{\mathrm{o}}(\mathrm{mg} / \mathrm{g})$ & 1.936 & 2.94 & 4.81 & 2.249 & 1.790 \\
\cline { 2 - 7 } & $\mathrm{E}(\mathrm{kJ} / \mathrm{Mole})$ & 0.825 & 0.824 & 0.823 & 0.808 & 0.795 \\
\hline
\end{tabular}

Table- 2: First- Order Kinetic Constants for Cadmium Adsorption.

\begin{tabular}{c|c|c|c|c}
\hline \multirow{2}{*}{$C_{i}(m g / L)$} & \multirow{2}{*}{$\mathrm{q}_{\mathrm{e}, \text { exp }}(\mathrm{mg} / \mathrm{g})$} & \multicolumn{3}{|c}{ Cadmium $(\mathrm{pH} 6.5)$} \\
\cline { 3 - 5 } & & $K_{\mathrm{f}}\left(\mathrm{min}^{-1}\right)$ & $q_{e q}, \mathrm{cal}_{(m g / g)}$ & $R^{2}$ \\
\hline 2 & 0.419 & 0.074 & 0.43 & 0.959 \\
\hline 4 & 0.694 & 0.666 & 0.678 & 0.992 \\
\hline 6 & 1.033 & 0.771 & 2.08 & 0.911 \\
\hline 8 & 1.299 & 0.912 & 2.16 & 0.899 \\
\hline 10 & 1.507 & 1.032 & 2.25 & 0.891 \\
\hline
\end{tabular}

Table-3: Second- Order Kinetic Constants for Cadmium Adsorption.

\begin{tabular}{c|c|c|c|c}
\hline \multirow{2}{*}{$C_{i}(m g / L)$} & \multirow{2}{*}{$\mathrm{q}_{\mathrm{e}, \mathrm{exp}}(\mathrm{mg} / \mathrm{g})$} & \multicolumn{3}{|c}{ Cadmium (pH 6.5) } \\
\cline { 3 - 5 } & & $k_{s}\left(\frac{g}{m g . \mathrm{min}}\right)$ & $q_{e q}, c$ & \\
\hline 2 & 0.419 & 0.180 & 0.489 & $R^{2}$ \\
\hline 4 & 0.694 & 0.055 & 0.870 & 0.996 \\
\hline 6 & 1.033 & 0.052 & 0.990 & 0.990 \\
\hline 8 & 1.299 & 0.050 & 1.142 & 0.992 \\
\hline 10 & 1.507 & 0.041 & 1.306 & 0.991 \\
\hline
\end{tabular}

\section{Intra particle diffusion and Elovich Models}

The $k p$ values were obtained from the slope of the straight-line portions of the plot of $q_{e q}$ versus $\left(t^{1 / 2}\right)$ for various temperatures. From the Table-4, it was observed that intra-particle rate constant values $\left(k_{p}\right)$ increased with solution temperature. The Fig.-8 shows that the straight line did not pass through the origin and this indicates that the intra-particle diffusion is not the only rate-controlling step.The values of initial 
adsorption rate $(\alpha)$ and desorption constant $(\gamma)$ were obtained from the slope and intercept of $q_{e q} v s \ln$ (t) and are tabulated in Table-5, along with $R^{2}$ coefficients for the cadmium adsorption process.

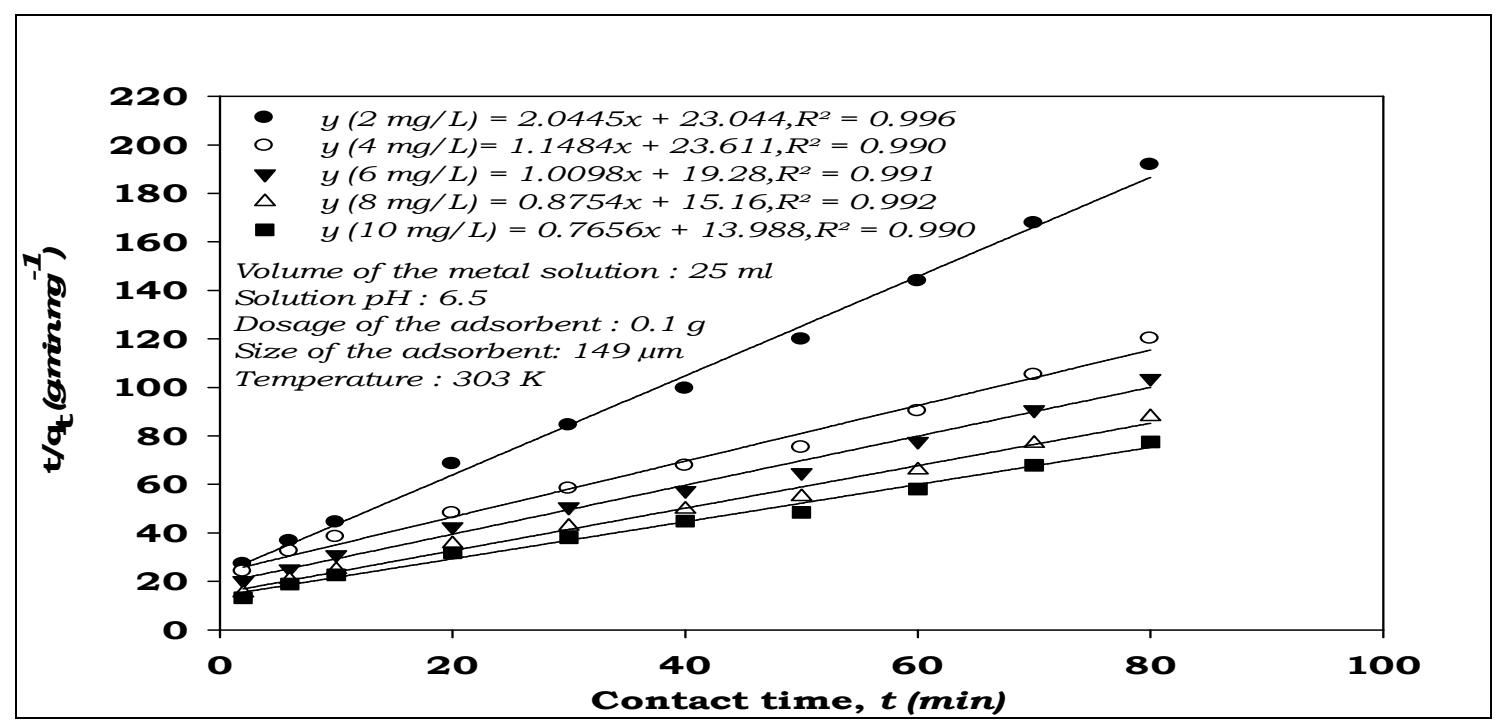

Fig.-7:Second-Order Kinetic Model for Adsorption of Cadmium.

The values were found to be quite acceptable based on the observed $R^{2}$ value.The theoretical $q_{e}$ values from the first order kinetic, Elovich and intra - particle diffusion models gave significantly different values compared to experimental values, and the correlation coefficients were also found to be lower. These results showed that the first- order kinetic, Intra-particle diffusion and Elovich models did not describe the sorption system. The results indicated that the calculated $q_{e}$ values were very close to the experimental $q_{e}$ values and the correlation coefficients were close to unity in the case of second - order kinetics for the adsorption of Cadmium ions. The applicability of second - order kinetic model confirm that the rate limiting step involved in the present process is chemisorption. The suitability of kinetic models followed in the order by second - order kinetic model $>$ First - order model $>$ Elovich model $>$ Intra-particle diffusion model. The experimental results obtained with activated carbon of Bauhinia Purpurea leaves as adsorbents was well fitted with the pseudo second - order kinetic model.

Table-4: Intra-Particle Diffusion Kinetic Constants for Cadmium Adsorption.

\begin{tabular}{c|r|r|r}
\hline \multirow{2}{*}{$C_{i}(m g / L)$} & \multicolumn{3}{|c}{ Cadmium $(\mathrm{pH} 6.5)$} \\
\cline { 2 - 4 } & \multicolumn{1}{|c}{$k_{p}$} & \multicolumn{1}{c}{$C$} & \multicolumn{1}{c}{$R^{2}$} \\
\hline 2 & 0.060 & 0.0127 & 0.981 \\
\hline 4 & 0.104 & 0.064 & 0.998 \\
\hline 6 & 0.118 & 0.0583 & 0.999 \\
\hline 8 & 0.1355 & 0.0436 & 0.998 \\
\hline 10 & 0.1532 & 0.0578 & 0.998 \\
\hline
\end{tabular}

Table-5: Elovich Kinetic Constants of Cadmium Adsorption Using Activated Carbons Prepared from Bauhinia Purpurea Leaves.

\begin{tabular}{c|c|c|c}
\hline \multirow{2}{*}{$C_{i}(m g / L)$} & \multicolumn{3}{|c}{ Cadmium $(\mathrm{pH} \mathrm{6.5)}$} \\
\cline { 2 - 4 } & $\gamma(g / m g)$ & $\left.\alpha_{(m g / g . m i n}\right)$ & $R^{2}$ \\
\hline 2 & 9.082 & 0.0923 & 0.988 \\
\hline 4 & 5.411 & 0.1036 & 0.957 \\
\hline 6 & 4.766 & 0.125 & 0.960 \\
\hline 8 & 4.15 & 0.158 & 0.963 \\
\hline 10 & 3.690 & 0.173 & 0.957 \\
\hline
\end{tabular}




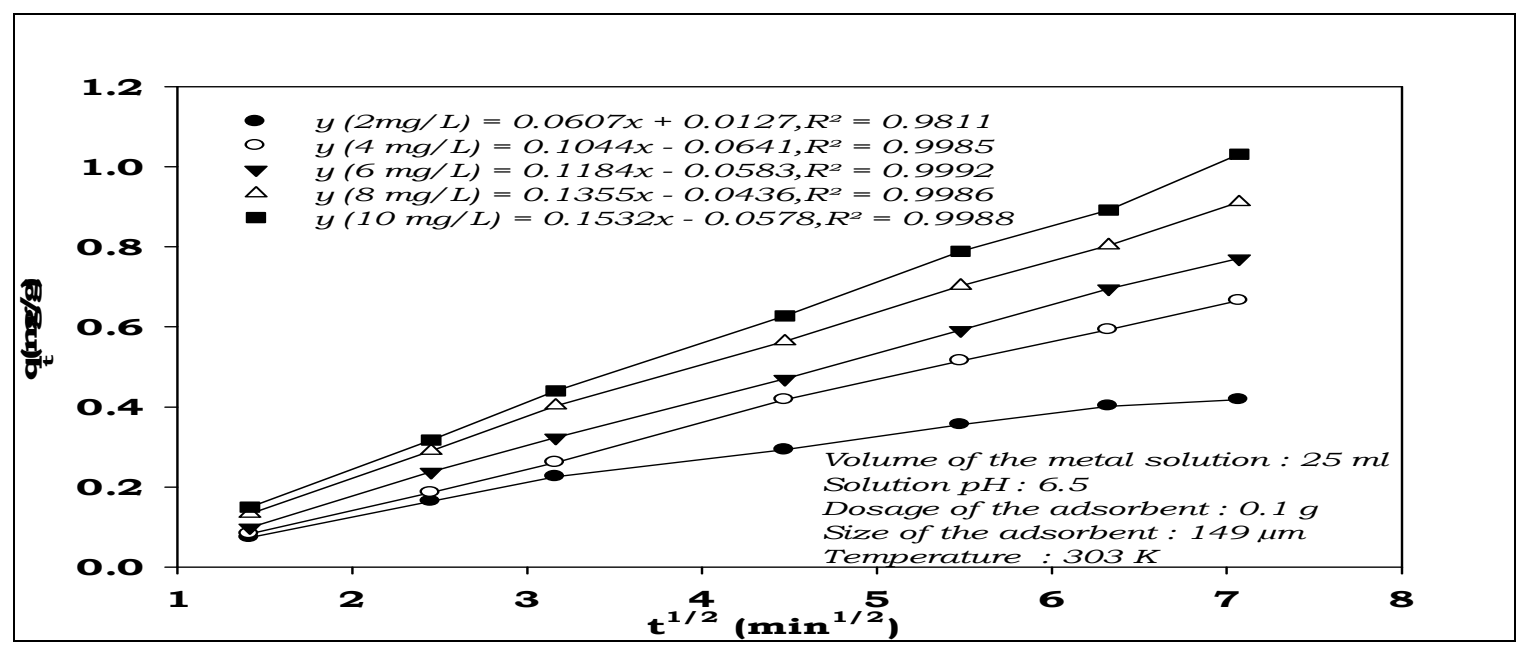

Fig.-8: Intra-Particle Diffusion Kinetic Model for Adsorption of Cadmium.

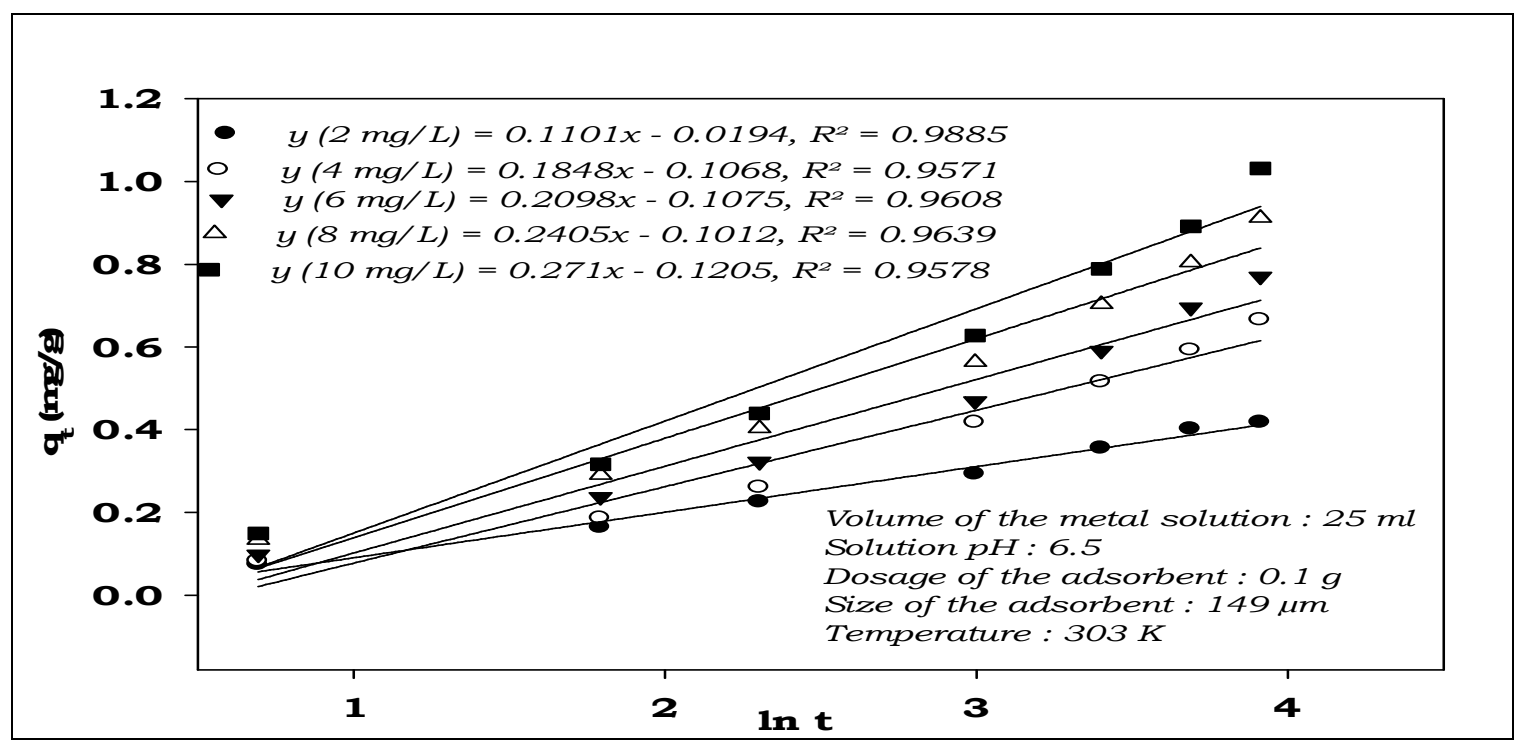

Fig.-9: Elovich Kinetic Model for Adsorption of Cadmium.

The following Isothermal and Kinetic model equations were correlated for Bauhinia Purpurea leaves for the adsorption of cadmium:

Table-6: Isothermal modeling of Cadmium adsorption.

\begin{tabular}{c|c|c}
\hline \multirow{2}{*}{ Isotherm } & Modeling & $\mathrm{R}^{2}$ \\
\cline { 2 - 3 } & $q_{e}=\frac{4 C_{e}}{1+4.344 C_{e}}$ & 0.951 \\
\hline Langmuir & $q_{e}=0.65 C_{e}^{0.26}$ & 0.982 \\
\hline Freundlich & $q_{e}=\frac{R T}{14502} \ln \left(53.63 C_{e}\right)$ & 0.956 \\
\hline Temkin & $q_{e}=0.133 e^{\left(-7.5 * 10^{-7}\right) \varepsilon^{2}}$ & 0.825 \\
\hline$R-D$ &
\end{tabular}

Table-7: Kinetic modeling of Cadmium adsorption.

\begin{tabular}{l|c|c}
\hline \multirow{2}{*}{ Model } & \multicolumn{2}{|c}{ Cadmium $\left(C_{i}: 2 \mathrm{mg} / \mathrm{L}\right)$} \\
\cline { 2 - 3 } & Kinetic model & $\mathrm{R}^{2}$ \\
\hline Psuedo - First order & $q_{t}=0.419\left(1-e^{-0.074 t}\right)$ & 0.959 \\
\hline
\end{tabular}


RASĀYAN J. Chem.

Vol. 11 | No. 3 |1376 - 1392| July - September | 2018

\begin{tabular}{l|c|c}
\hline Psuedo - Second order & $\frac{d q_{t}}{d t}=0.180\left(0.419-q_{t}\right)^{2}$ & 0.996 \\
\hline Elovich & $\frac{d q_{t}}{d t}=0.0923 e^{\left(9.082 q_{t}\right)}$ & 0.988 \\
\hline Intra-particle diffusion & $q_{t}=0.045 t^{0.5}+0.026$ & 0.964 \\
\hline
\end{tabular}

\section{Characterization of Adsorbent}

Figures-10(a) and 10(b) shows the SEM micrographs of activated carbon of Bauhinia Purpurea leaves after adsorption of cadmium.It is evident from the figure that the adsorbent is highly heterogeneous and the surface morphology of the adsorbent is rough. It is clear that the adsorbent has a considerable number of heterogeneous layer pores where there is a good possibility of heavy metal to be adsorbed.The surface texture of activated carbon of Bauhinia Purpurea leaves was completely changed before and after adsorption of heavy metals. The surface of the metal-loaded adsorbent clearly shows that the surface of the adsorbent dosage was covered with metal ions. The pores were completely filled with the metal ions after the adsorption of cadmium and the pores appear to be smooth. This observation indicates that the metal is adsorbed to the functional groups present in the pores. The surface of the adsorbent became smooth after the adsorption of cadmium ions. Smoothening of the surface is due to the adsorption of metal ions onto the pores of the adsorbent. It may also occur due to the decrease in the surface heterogeneity of the adsorbent.

The functional groups present in the activated carbon of Bauhinia Purpurea leaves were investigated by FTIR spectra within the range of $400-4000 \mathrm{~cm}^{-1}$ wave number. Figures-11(a) and 11(b)show the band positions in the FTIR spectra of the activated carbon of Bauhinia Purpurea leaves before and after adsorption cadmium and presented in Table-6. The adsorption spectra displayed a number of adsorption peaks indicating the complex nature of the activated carbon of Bauhinia Purpurea leaves and it was composed of various functional groups which are responsible for the binding of cadmium ions. The broad peak at $3000 \mathrm{~cm}^{-1}$ corresponds to the $\mathrm{C}-\mathrm{H}, \mathrm{O}-\mathrm{H}$ and $=\mathrm{C}-\mathrm{H}$ stretching vibrations of alkanes, aromatic and carbonyl acids, thus showing the presence of free hydroxyl groups on the adsorbent surface. The peaks at range from 3850 to $3740 \mathrm{~cm}^{-1}$ are due to stretching vibration of $\mathrm{O}-\mathrm{H}$. The peak at $2850 \mathrm{~cm}^{-1}$ represents the symmetric $\mathrm{C}-\mathrm{H},=\mathrm{C}-\mathrm{H}, \mathrm{O}-\mathrm{H}$ and $(\mathrm{C}=\mathrm{O}) / \mathrm{C}-\mathrm{C}$ stretching of Alkanes/ Aldehydes/Carbonyl acids functional groups present on the adsorbent surface. The sharp peak at $1650 \mathrm{~cm}^{-1}$ could be due to the $\mathrm{C}=\mathrm{C}, \mathrm{C}=\mathrm{O}$ stretching of alkene, carbonyl and amide stretch. The carboxylic acid groups take part in the adsorption of metal ions from the aqueous solution in addition to the other active sites on the carbon surface. The peak at $1680 \mathrm{~cm}^{-1}$ is attributed to the graphite's characteristic $\mathrm{sp}^{2}$ hybridized $\mathrm{C}=\mathrm{C}$ aromatic skeletal stretching. The peak present at $1500 \mathrm{~cm}^{-1}$ represents the $\mathrm{NH}$ (bending) and $\mathrm{NO}$ (stretch) stretching vibration of amide and nitro functional groups on the adsorbent surface. While the band at $1350 \mathrm{~cm}^{-1}$ corresponds to the C-F, $\mathrm{C}-\mathrm{N}$, and $\mathrm{N}$-Stretching vibrations of alkyl halide, amine and nitro functional groups on the adsorbent surface. It is concluded that the prepared activated carbon material includes oxygen-containing functional groups that provide additional active sites for the adsorption process. After adsorption of cadmium, the asymmetrical stretching, and vibration at $3850 \mathrm{~cm}^{-1}$ were shifted to $3890 \mathrm{~cm}^{-1}$. This shift in peak indicates the interaction between cadmium and $-\mathrm{OH}$ groups of adsorbent due to the presence of alcohols, phenols and carboxylic acid. A new peak at $2800 \mathrm{~cm}^{-1}$ was observed due to the chemical reaction involved in the adsorption process. The peak $\mathrm{C}=\mathrm{O}$ stretch at $1650 \mathrm{~cm}^{-1}$ and $1350 \mathrm{~cm}^{-1}$ were shifted to $1625 \mathrm{~cm}^{-1}$, and $1300 \mathrm{~cm}^{-1}$ due to the presence of carboxyl groups. After cadmium deposition on the adsorbent surface, the peak of $1500 \mathrm{~cm}^{-1}$ was disappeared. The shift in peak values could be due to the formation of a chemical bond between the functional groups present on activated carbon of Bauhinia Purpurea leaves and cadmium.FTIR spectrum of raw activated carbon of Bauhinia Purpurea leaves reveals that there were a large number of hydroxyl and carboxyl groups present on the surface of the adsorbent, which possibly reacted with metal ions in aqueous solution. These groups may largely contribute to the active adsorption sites required for the adsorption of cadmium metal ions. These results also indicate that chemisorption could also be involved in the adsorption of cadmium. 
RASĀYAN $J$. Chem.

Vol. 11 | No. 3 |1376 - 1392| July - September | 2018

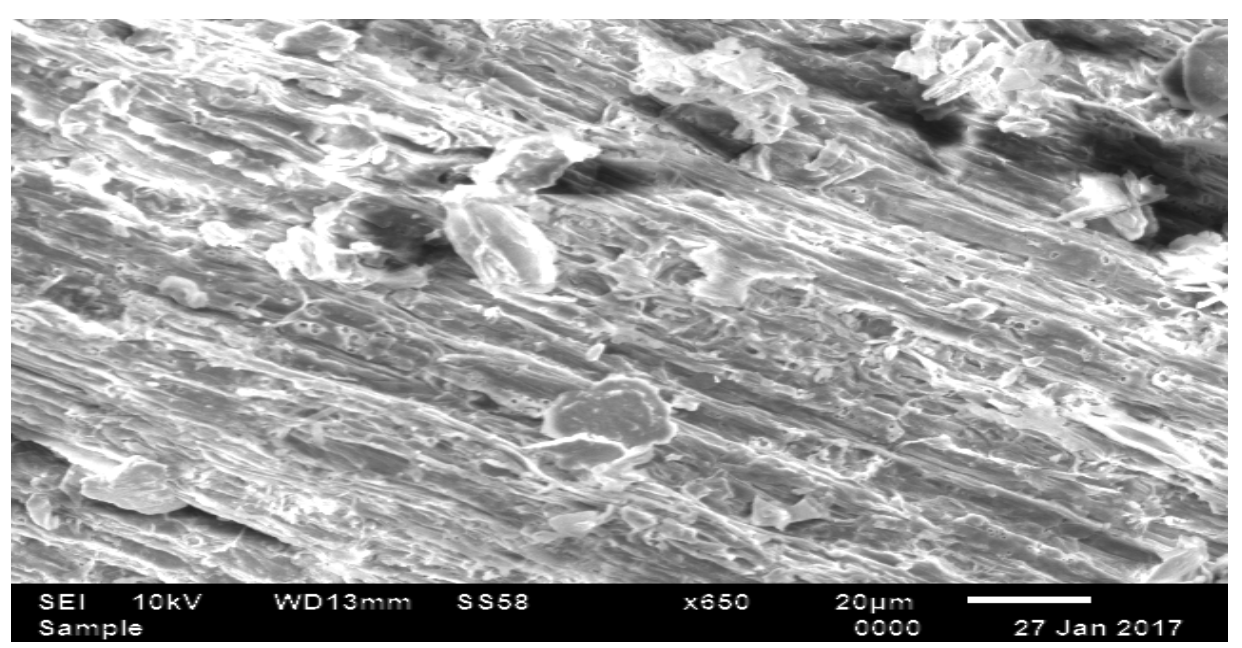

(a)

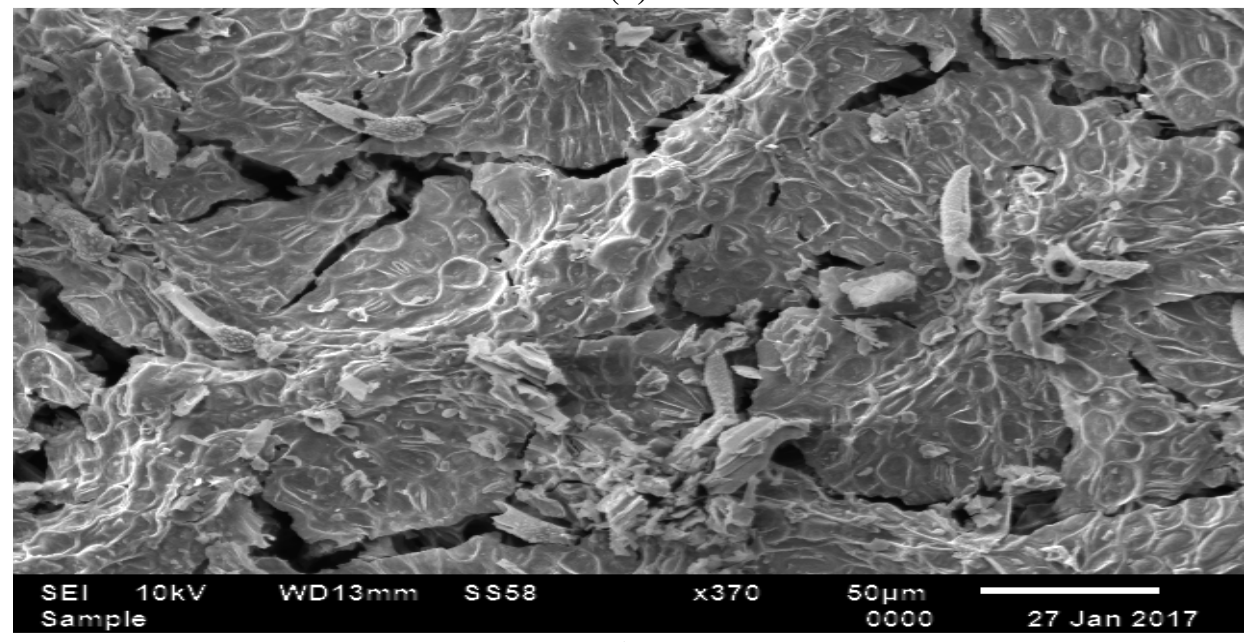

(b)

Fig.-10: SEM Micrographs of Activated Carbon of Bauhinia Purpurea Leaves Before(a) and After adsorption(b) of Cadmium.

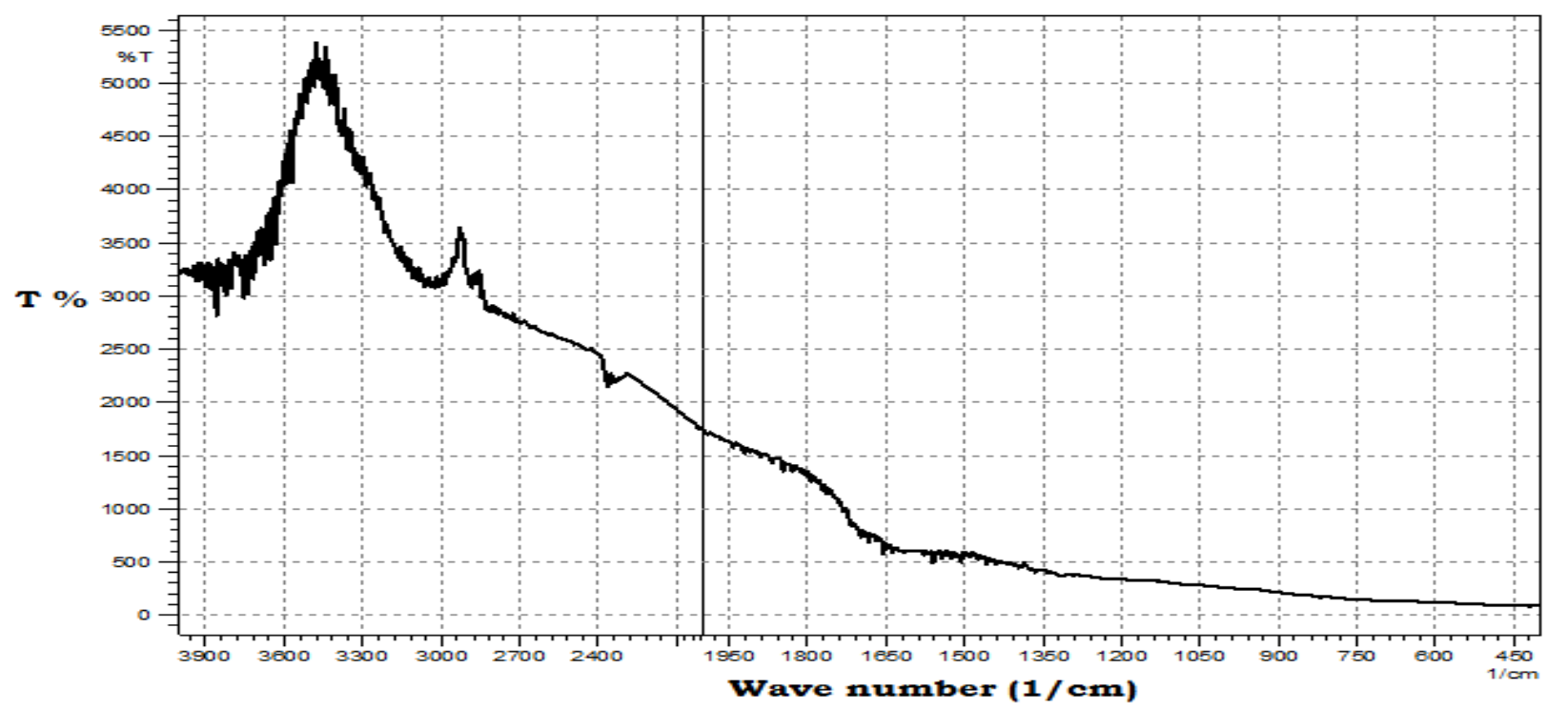

(a) 


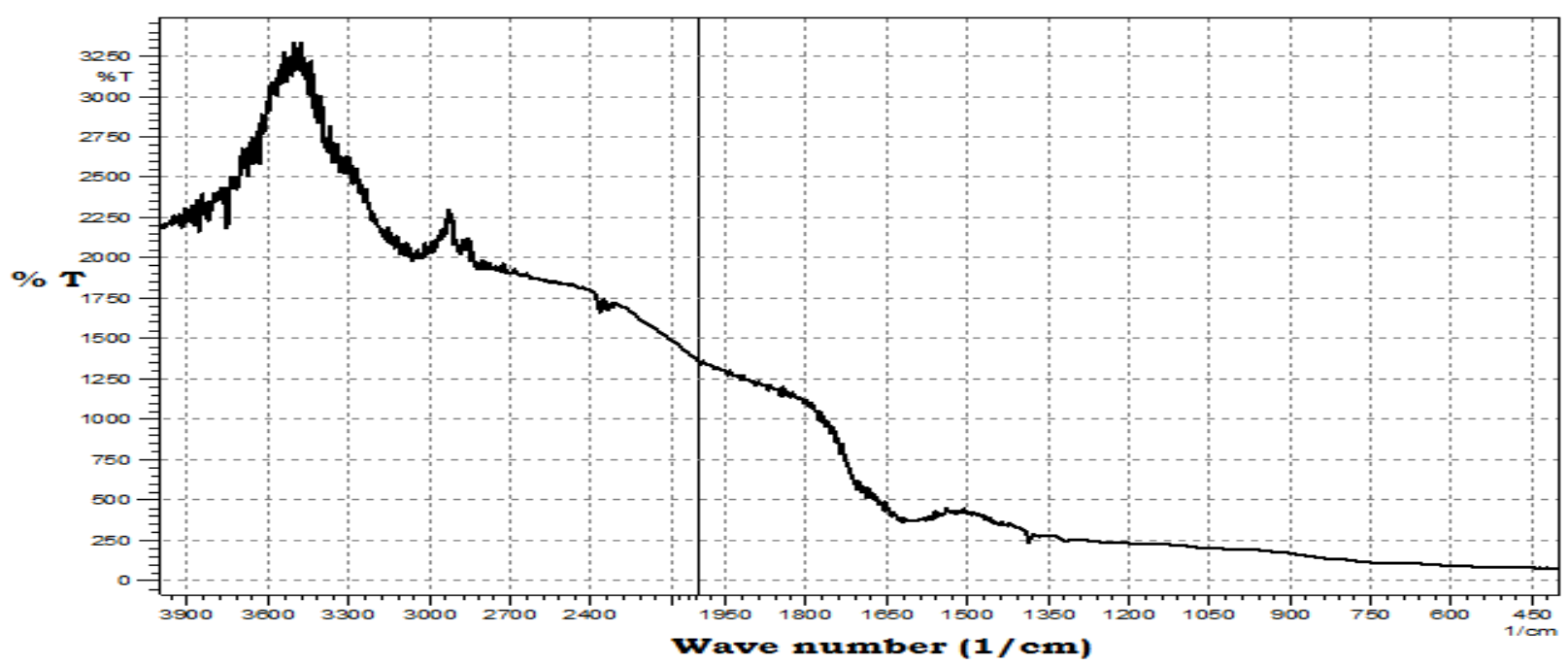

(b)

Fig.-11: FTIR Spectra of Activated Carbon of Bauhinia Purpurea Leaves Before(a) and After Adsorption (b) of Cadmium.

Table-6: FTIR Spectra of Activated Carbon Prepared from Bauhinia Purpurea Leaves

\begin{tabular}{|c|c|c|c|c|}
\hline \multicolumn{3}{|c|}{ IR frequency range, $\left(\mathrm{cm}^{-1}\right)$} & \multicolumn{2}{|c|}{ Activated carbon prepared from Bauhinia Purpurea leaves } \\
\hline ACBPL & Cd loaded & Diff. & Type of vibration & Functional groups \\
\hline 3850 & 3890 & 40 & $\mathrm{OH}$, Stretch, free & Alcohols \\
\hline 3740 & 3750 & 10 & $\mathrm{OH}$, Stretch,free & Alcohols \\
\hline 3000 & 3075 & 75 & $\begin{array}{l}\text { C-H, Stretch } \\
=\mathrm{C}-\mathrm{H}, \text { Stretch } \\
\text { C-H, Stretch }\end{array}$ & $\begin{array}{l}\text { Alkane/Alkene/ } \\
\text { Aromatics }\end{array}$ \\
\hline 2890 & 2850 & 40 & $\begin{array}{l}\text { C-H, Stretch } \\
=\mathrm{C}-\mathrm{H}, \text { Stretch } \\
\text { O-H, Stretch }(\mathrm{C}=\mathrm{O})\end{array}$ & $\begin{array}{l}\text { Alkanes/ Aldehydes/ } \\
\text { Carbonyl acids }\end{array}$ \\
\hline 2850 & 2800 & 50 & $\begin{array}{l}\text { C-H, Stretch } \\
=\mathrm{C}-\mathrm{H}, \text { Stretch } \\
\mathrm{O}-\mathrm{H}, \text { Stretch }(\mathrm{C}=\mathrm{O})\end{array}$ & $\begin{array}{l}\text { Alkanes/ Aldehydes/ } \\
\text { Carbonyl acids }\end{array}$ \\
\hline 2390 & 2390 & 0 & - & - \\
\hline 1650 & 1625 & 25 & $\begin{array}{l}\mathrm{C}=\mathrm{C} \text {, stretch } \\
\mathrm{NH}, \text { Bending } \\
\mathrm{C}=\mathrm{C} \text {, stretch } \\
\mathrm{C}=\mathrm{O} \text {, stretch } \\
\mathrm{NH}, \text { Bending }\end{array}$ & $\begin{array}{l}\text { Alkene/Amine/ Aromatics } \\
\text { /Amide }\end{array}$ \\
\hline 1500 & - & - & $\begin{array}{l}\text { C-H, Stretch } \\
\text { O-H, Stretch } \\
=\mathrm{C}-\mathrm{H}, \text { Stretch } \\
\text { NO, Stretch }\end{array}$ & $\begin{array}{l}\text { Alkane/Carbonyl } \\
\text { acid/Aldehydes/ } \\
\text { Nitro }\end{array}$ \\
\hline 1350 & 1380 & 30 & $\begin{array}{l}\text { C-F, Stretch } \\
\text { C-N, Stretch } \\
\text { N-O, Stretch }\end{array}$ & $\begin{array}{l}\text { Alkyl Halide/Amine/ } \\
\text { Nitro }\end{array}$ \\
\hline 450 & 450 & 0 & - & - \\
\hline
\end{tabular}


RASĀYAN J. Chem.

Vol. 11 | No. 3 |1376 - 1392| July - September | 2018

Table-7: XRD Details of Activated Carbon of Bauhinia Purpurea Leaves Before, and After Adsorption of

\begin{tabular}{c|c|c}
\multicolumn{3}{|c}{ Cadmium. } \\
\hline Count /Sec & $\begin{array}{c}\text { Peak Position }(2 \theta) \\
\text { Before Adsorption }\end{array}$ & $\begin{array}{c}\text { Peak Position }(2 \theta) \\
\text { by Cadmium Loaded }\end{array}$ \\
\hline 31.74 & 9.4230 & 18.5928 \\
\hline 521.63 & 18.7038 & 18.8552 \\
\hline 162.55 & 22.4870 & 22.5708 \\
\hline 110.91 & 24.8137 & 24.7547 \\
\hline 198.81 & 30.0364 & 30.1972 \\
\hline 30.02 & 31.2790 & 33.6767 \\
\hline 79.33 & 33.5363 & 34.9539 \\
\hline 81.28 & 34.9501 & 40.4934 \\
\hline 17.50 & 38.1884 & 43.2529 \\
\hline 61.19 & 40.3130 & 48.2378 \\
\hline 40.69 & 43.2591 & 51.5447 \\
\hline 26.68 & 44.2534 & 57.9088 \\
\hline 34.03 & 46.7713 & 18.5928 \\
\hline 46.69 & 48.2610 & 18.8552 \\
\hline 41.90 & 51.4902 & 22.5708 \\
\hline 31.74 & 9.4230 & 24.7547 \\
\hline 521.63 & 18.7038 & 30.1972 \\
\hline 162.55 & 22.4870 & 33.6767 \\
\hline
\end{tabular}

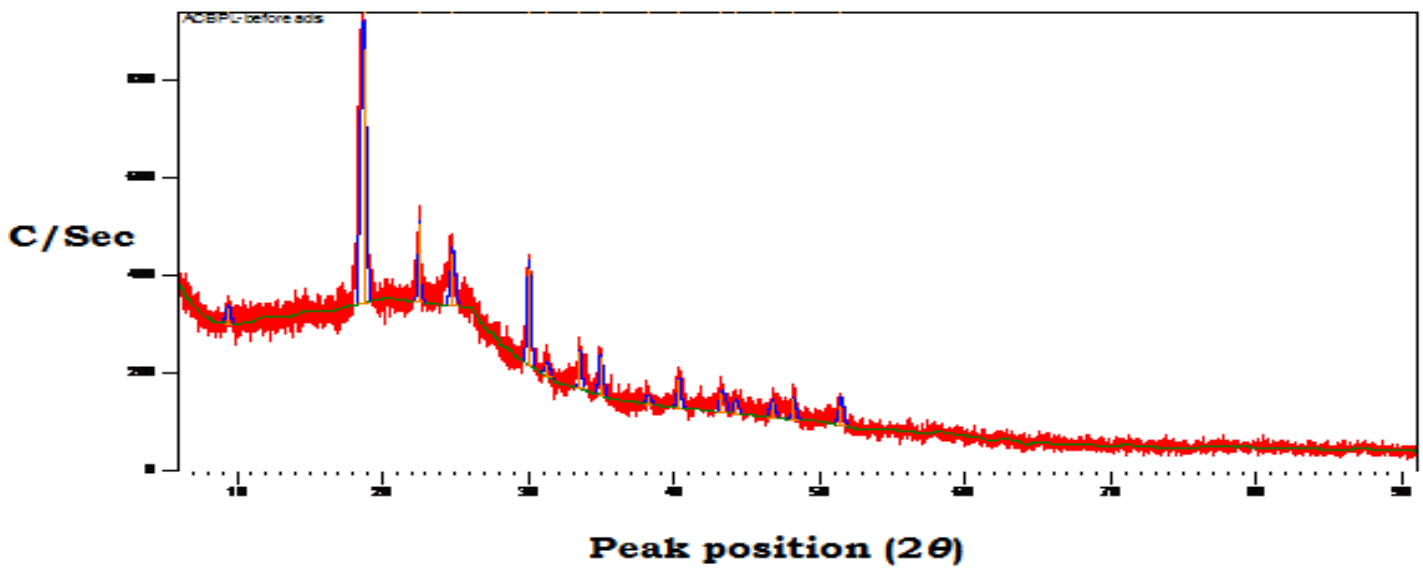

(a)

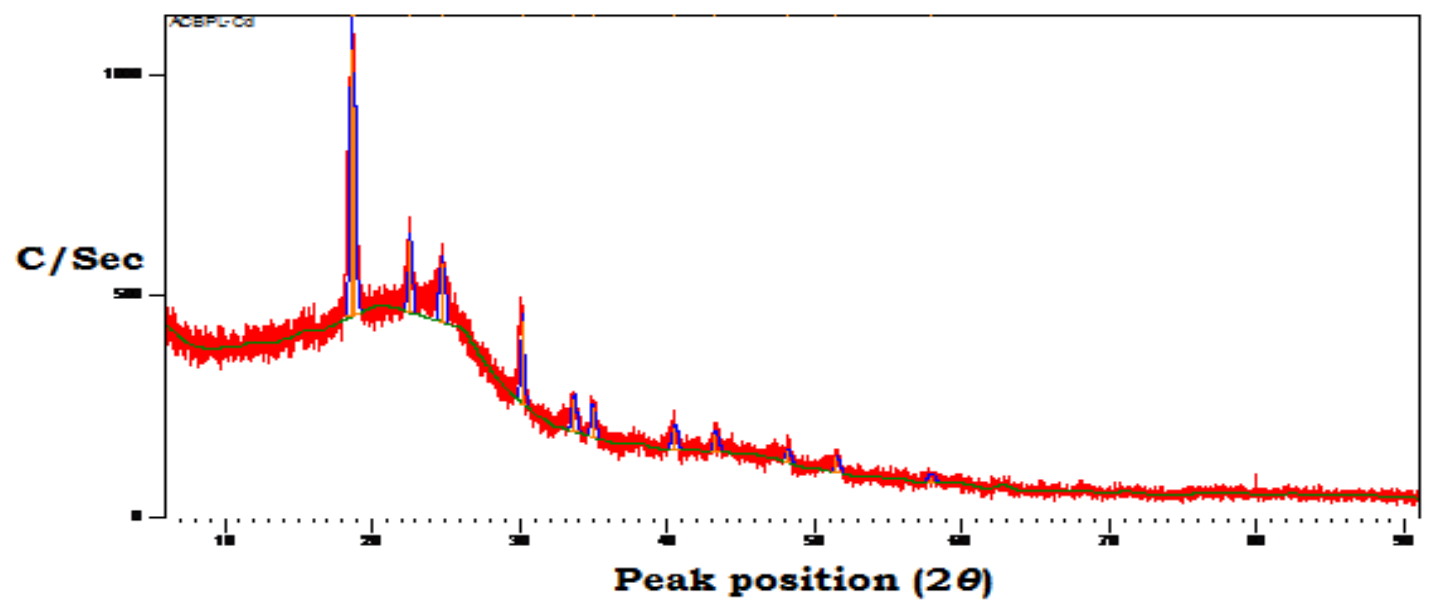

(b)

Fig.-12: XRD of Activated Carbon of Bauhinia Purpurea Leaves Before (a) and After Adsorption (b) of Cadmium. 
The adsorbent can be crystallographically characterized by means of X-ray diffraction (XRD). Figures12(a) and 12(b) shows the XRD diagram of the activated carbon of Bauhinia Purpurea leaves before and after adsorption of cadmium metal ions. The XRD pattern of raw adsorbent showed a typical spectrum of cellulosic material, with main and secondary peaks at $2 \theta$ of $18.60^{\circ}$ and $22.45^{\circ}$ respectively. The height of the peak and corresponding position angles are shown in Table-7. The main peak at $18.60^{\circ}$ corresponds to the (002) crystallographic planes and it is taken as indicative of the presence of highly organized crystalline cellulose ${ }^{29}$. The secondary peak at $22.45^{\circ}$ corresponding to the (101) crystal plane and it is a measure of a less organized polysaccharide structure. The planes at (002) and (101) indicate the presence of a negative form of cellulose found in the natural source that is cellulose-I polymorphic form. The presence of cellulose indicates the irreversible adsorption of metals through coloumbic attraction since the negative surface change is acquired by cellulose on contact with water ${ }^{31}$. The cellulose present in the natural materials contains some crystalline oriented zones, which give a certain degree of crystallinity in fiber materials. The XRD pattern of raw the activated carbon of Bauhinia Purpurea leaves showed a characteristic peak at a $2 \theta$ value of $18.60^{\circ}$. The peaks at $22.72,29.47,33.59,34.92,40.3,43.13$ and $48.21^{\circ}$ corresponding to the peak height (count/Sec) was slightly changed to $24.72,30.07,33.58,34.93$, $40.35,43.23$ and $48.15^{\circ}$ for cadmium adsorption. The shift in peaks, disappearance of peak and formation of new peaks after adsorption of cadmium samples was due to the chemical reaction involved during the process. Thus, XRD results confirmed that the significant interactions were occurring between metal ions and the adsorbent surface.These variations in adsorption capacity could be due to the difference in the properties of the adsorbents such as active surface area, porosity, functional groups, etc. The abundant availability, cost effectiveness, better adsorption capacity rates suggested that the activated carbons prepared fromBauhinia Purpurea leaves can be an efficient and effective adsorbent for the removal of cadmium from the effluents.

\section{CONCLUSION}

The following conclusions could be drawn from the present study on the removal of cadmium from aqueous solutions using adsorption technique:

- It was found that for activated carbon Bauhinia Purpurea leaves, the experimental data were very well represented by Freundlich isotherm for the removal of cadmium from the solution.

- The adsorption activation energy $(E)$ values for the given adsorbent under study was decreased with an increase in solution temperature. It was observed that the scope of an ordinary free energy credited to physical adsorption and the force of attraction between the adsorbate and adsorbent is very weak, therefore this type of adsorption can be easily reversed by heating or by decreasing the pressure.

- Kinetic studies indicated that the adsorption process followed well with the pseudo second-order kinetic model for the adsorption of cadmium using activated carbons of Bauhinia Purpurea leaves for the range of initial metal concentrations studied for the entire adsorption period.

- SEM micrographs showed the binding of metal ions on the surface the adsorbents. FTIR analysis indicated the presence of various functional groups such as hydroxyl, carboxyl, amino, etc., on the surface of the adsorbent which was responsible for the adsorption of metals. XRD studies confirmed the crystalline and amorphous nature of the adsorbents.

\section{REFERENCES}

1. M. A.Momodu, and C.A. Anyakora, Res. J. Environ. Earth Sci., 2 (1), 39(2010).

2. O. S. Amuda, A. A. Giwa andI. A. Bello, Biochem. Eng. J., 36, 174(2007).

3. A .Doyurum and Celik, J. Hazard. Mater., 138,22 (2006).

4. Deswati, Hamzar Suyani, Rahmiana Zein, Admin Alif and Hilfi Pardi, Rasayan J. Chem., 10(2), 549 (2017), DOI: 10.7324/RJC.2017.1021591.

5. F.Boudrahem, B. F.Aissani and A. H.Amar, J. Environ. Manage., 90,3031(2009).

6. N.Kannan and G. Rengasamy, Water Air Soil Pollut.,163,185(2005).

7. K. A. Krishnan and T.S. Anirudhan, Ind. Eng. Chem. Res., 41, 5085 (2002).

8. J.Febrianto, A.N.Kosasih, J.Sunarso, Y.H.Ju, N.Indraswati and S.Ismadji,J. Hazard. Mater., 162, 616 (2009).

9. F.Fu and Q. Wang, J. Environ. Manage., 92,407(2011).

\section{CADMIUM ADSORPTION IN AN AQUEOUS SOLUTION}


RASĀYAN J. Chem.

Vol. 11 | No. 3 |1376 - 1392| July - September | 2018

10. C. Sumithra, and K.Sakthikeyan, Rasayan J.Chem, 7, 149 (2014).

11. T. Fan, Y. Liu, B. Feng, G. Zeng, C. Yang, M. Zhou, H. Zhou, Z. Tan and X. Wang, J. Hazard.Mater., 160, 655(2008).

12. K. Mona, K.Ahmad and H.Hanafy,Energy Procedia, 50, 113(2014).

13. G.Venkatesan and U. Senthilnathan, Research Journal of Chemistry and Environment, 17, 5(2013).

14. Lakshmi Adathodi, Raja Murugadoss J. and Kalyani Gaddam, Rasayan J. Chem., 11 (3), 1204 (2018), DOI: 10.31788/RJC.2018.1134009.

15. O. Gercel, H. F. Gercel, Chemical Engineering Journal, 132, 289(2007).

16. H. BehzadSusana, C. Rodriguez, A. Mohammad, A. Ghouti, M. Asif, T. Inderjeet, A. Shilpi and G. Vinod Kumar, Journal of Molecular Liquids 208, 99(2015).

17. M. Momcilovic, M. Purenovic, A.Bojic, A. Zarubica and M. Randelovid, Desalination, 276, 53 (2011).

18. G. Kalyani, Y. Prasanna Kumar and P. King, Rasayan J. Chem., 9 (3), 510 (2016).

19. H. L. Yadav and A.Jamal, Rasayan J. Chem., 10(3), 1062 (2017), DOI:10.7324/RJC.2017.1031775.

20. N.K .Akunwa, M.N. Muhammad and J. C. Akunna, J. Environ. Manage, 146, 517 (2014).

21. P.Deba sree, M. Umesh and B.Swarup, Journal of Water Process Engineering, 2, 105 (2014).

22. A. M.Awwad and M. Salem, Journal of Saudi Chemical Society, 18, 486 (2014).

23. I. G. Umar, O. Emmanuel and H.A. Abdul, Springer plus, 4, 458 (2015).

24. K. Y.Foo and B.H.Hameed, Rev. Chem. Eng., 156, 2 (2010).

25. H. Joga Rao, P.King and Y.Prasanna Kumar, Rasayan J.Chem., 9(2), 254(2016).

26. M.M.Olga,Freitas, J.E.Ramiro, Martins and M.Cristina, Delerue-Matos, A.R.Rui and Boaventura,J. Hazard. Mater., 153 ,493 (2008).

27. A.K. Wanjari and U. E. Chaudhari, Rasayan J. Chem., 10(1), 82 (2017), DOI: $10.7324 /$ RJC.2017.1011556.

28. M. Mohamed, Ghoneim, S. Hanaa, E. Desoky, M. Khalid, E. Moselhy, A.Adel, H. Emad, E. N. Abou, I. Lamiaa and A.E.Prol, Egyptian Journal of Aquatic Research, 40, 235(2014).

29. W. Sadia, D. M.Imran, N. Saira and A. Rasool, Arab. J. Chem., 7, 1091 (2014).

30. J. S. Leandro, R. P. Fernanda, A. A. Luiz, H. Crispin and C. Garcia, Water. Treat., 52, 7878 (2014).

31. P. Girods, A. Dufour, V. Fierro, Y. Regime, C. Rogaumea and A. Zoulaliana, J. Hazard.Mater., 188, 917 (2011).

[RJC-4035/2018] 